\title{
Reformas do Estado e da educação e as políticas públicas para a formação de professores a distância: implicações políticas e teóricas
}

\author{
João dos Reis Silva Júnior \\ Pontifícia Universidade Católica de São Paulo, \\ Programa de Pós-Graduação em Educação: História, Política e Sociedade. \\ Universidade de Sorocaba, Programa de Pós-Graduação em Educação
}

\section{Introdução}

A década de 1980 foi considerada como a década perdida para a economia brasileira; ao mesmo tempo, nela vivemos um intenso processo de redemocratização do país: uma visível contradição, cuja síntese parece ter sido a mudança nas estruturas sociais produzida durante a década de 1990. Um processo que se iniciou com o Governo Collor de Mello, teve uma transição no Governo de Itamar Franco, mas consolidou-se com Fernando Henrique Cardoso. Este anunciou, em discurso de despedida do Senado, em novembro de 1994, que as eleições daquele ano colocariam "um ponto final na transição"; que "depois de dezesseis anos de marchas e contramarchas, [o regime político brasileiro] [...] [parecia] finalmente chegar ao porto seguro de uma democracia consolidada [...]". Mas, para além da transição de um regime militar autoritário para um regime democrático, aquele momento histórico, para Fernando Henrique Cardoso, representava a mudança paradigmática de ciclos de desenvolvimento, estabelecendo uma ruptura com o que chamou de "Era Vargas". No discurso referido, reiterava:
Acredito firmemente que o autoritarismo é uma página virada na história do Brasil. Resta, contudo, um pedaço do nosso passado político que ainda atravanca o presente e retarda o avanço da sociedade. Refiro-me ao legado da Era Vargas, ao seu modelo de desenvolvimento autárquico e ao seu Estado intervencionista. Esse modelo, que à sua época assegurou progresso e permitiu a nossa industrialização, começou a perder fôlego nos fim dos anos 70. Atravessamos a década de 80 às cegas, sem perceber que os problemas conjunturais que nos atormentavam - a ressaca dos choques do petróleo e dos juros externos, a decadência do regime autoritário, a superinflação - mascaravam os sintomas de esgotamento estrutural do modelo varguista de desenvolvimento. No final da "década perdida" - assim chamada, às vezes, com injustiça -, os analistas políticos e econômicos mais lúcidos, das mais diversas tendências, já convergiam na percepção de que o Brasil vivia não apenas um somatório de crises conjunturais, mas o fim de um ciclo de desenvolvimento de longo prazo. Que a própria complexidade da matriz produtiva implantada excluía novos avanços da industrialização por substituição de importações. Que a manutenção dos mesmos padrões de protecionismo $e$ intervencionismo estatal sufocava a concorrência neces- 
sária à eficiência econômica e distanciaria cada vez mais o Brasil do fluxo das inovações tecnológicas e gerenciais que revolucionavam a economia mundial. E que a abertura de um novo ciclo de desenvolvimento colocaria necessariamente na ordem do dia os temas da reforma do Estado e de um novo modo de inserção do País na economia internacional. Isto começou a acontecer no governo anterior ao do Presidente Itamar Franco. Infelizmente, de uma maneira atabalhoada, num ambiente político poluído por uma coorte de desatinos. Devemos à extraordinária sensibilidade política do Presidente Itamar Franco que esse resultado não tenha sido levado pelo furacão que colheu seu antecessor. Nas circunstâncias dificílimas que todos conhecemos, guiado pelo radar da intuição do estadista que hoje o Brasil aclama, Sua Excelência conseguiu salvar do naufrágio aquilo que merecia ser salvo: as medidas no sentido da abertura externa e da desestatização da economia; mas sobretudo a manutenção, na agenda política, das reformas fundamentais para um novo modelo de desenvolvimento. (Cardoso, 1994, grifos meus)

Observa-se, no discurso, o que hoje se apresenta como ditadura do Poder Executivo em detrimento dos demais poderes - um hiperpresidencialismo, nas palavras de Guilherme O'Donnel -, ao lado de uma desnacionalização econômica e de um Estado reprodutor, no que se refere à economia, e caritativo e fiscalizador, no que se refere à esfera social. Em acréscimo, trata-se de um Estado contraditório: forte e centralista, além de interventor em relação ao âmbito nacional e servil no âmbito internacional, ante a universalização do capitalismo comandada pelos organismos multilaterais com a anuência e a efetiva participação dos governos dos países periféricos. Quadro a que chegamos por meio de um processo socioeconômico e político capitaneado pelo Governo de Fernando Henrique Cardoso, que para levá-lo a termo lançou mão de um intenso programa de reformas institucionais.

O referido pronunciamento, quando analisado no contexto daquele momento, cujo fato central consistiu no impedimento do presidente Collor de Mello, indica um movimento em cuja lógica punha-se uma necessidade de continuidade e de simultânea ruptura.
Continuidade do projeto político que se iniciava nos primórdios dos anos de 1990 e ruptura da articulação que se fizera em torno do presidente Collor. Uma nova aliança para sustentação do projeto político pretendido impunha-se aos dirigentes brasileiros. Ela fora produzida ao longo do Governo de Itamar Franco, aparentemente, com base no então popular Plano Real, pondo como parceiros a "academia paulista-carioca" e os tradicionais políticos do Norte e Nordeste do país. Fiori (1995) já anunciava o que hoje se tornou uma penosa realidade, ao mesmo tempo que nos permite melhor compreender a nossa conjuntura atual:

A ilustrativa figura de linguagem [Consenso de Washington, matriz do Plano Real e de tantos outros em nível planetário a orientar não só a economia, mas, sobretudo, as mudanças sociais e as reformas institucionais brasileiras], hoje de domínio público internacional, refere-se a um plano único de ajustamento das economias periféricas, chancelado pelo FMI e pelo Bird em mais de 60 países de todo o mundo, configurando uma estratégia de homogeneização das políticas econômicas nacionais, operadas, em alguns casos, como em boa parte da África - começando pela Somália, no início de 80 - diretamente pelos próprios técnicos daquelas agências; em outros, como para exemplificar, na Bolívia, na Polônia e mesmo na Rússia até há bem pouco tempo, com a ajuda de economistas universitários norte-americanos; e, finalmente, em países com corpos burocráticos mais estruturados, pelo que Williamson apelidou de technopols, ou seja, economistas capazes de somar ao perfeito manejo do seu mainstream (evidentemente neoclássico e ortodoxo) a capacidade política de implementar nos seus países a mesma agenda do consensus, como é ou foi o caso, para exemplificar, de Aspe, Salinas e Zedillo, no México; de Cavallo, na Argentina; de Yegor Gaidar na Rússia; de Lee Teng-hui, em Taiwan; Manmohan Singh, na Índia; ou mesmo Turgut Ozal, na Turquia; e, a despeito de tudo, Zélia e Kandir, seguidos de Malan, Arida, Bacha e Franco, no Brasil. (p. 234, grifos meus)

Destaca-se nas palavras de Fiori a produção de um ajuste econômico mundial decorrente da universalização do capitalismo tanto no campo geográfico 
como no social. Por um lado, vale observar que tal plano tem origem na produção, nos diagnósticos e nas pesquisas dos bons intelectuais dos países de pertença da economia central em âmbito planetário, com predomínio dos Estados Unidos da América, e daqueles já ligados às agências multilaterais, com destaque para o Banco Mundial, além de universidades engajadas na resolução de problemas mundiais, sob a orientação de um repertório econômico (evidentemente neoclássico e ortodoxo)". Por outro lado, o compromisso assumido pelo Brasil em sua agenda econômica e política foi seguido de outros numerosos compromissos na esfera social, particularmente na esfera educacional, tais como os que se fizeram por meio dos documentos políticos: Declaração Mundial de Educação para Todos, de Jomtien (UNESCO, 1990), e Declaração de Nova Delhi (UNESCO, 1993), ${ }^{1}$ que tiveram sua primeira expressão orgânica do movimento reformista mundial, na esfera da educação, no Brasil, com o Plano Decenal de Educação para Todos e, na esfera executiva, no Planejamento Político-Estratégico do Ministério da Educação 1995/ 1998, tornado público em 1995 . $^{2}$ Convém, aqui, ob-

${ }^{1}$ Os países emergentes reiteraram, em 1993, o compromisso de atender às necessidades básicas de aprendizagem e convocaram as instituições financeiras internacionais para que, sob o prisma de ajustes estruturais, reconhecessem a educação como investimento crítico (UNESCO, Declaração de Nova Delhi, 16 de dezembro de 1993, grifos meus).

${ }^{2}$ Destaca-se ainda, como parte do Plano Decenal de Educação para Todos, o Compromisso Nacional de Educação para Todos, firmado pelos participantes da Semana Nacional de Educação para Todos, reunidos em Brasília-DF de 10 a 14 de maio de 1993, com vistas a orientar a construção do Plano”. Assinam tal compromisso aproximadamente 130 participantes, incluindo autoridades, em sua grande maioria, representantes das secretarias estaduais de educação, delegacias de ensino, conselhos estaduais de educação, e representantes de outras entidades, desde universidades até a Confederação Nacional das Indústrias e a Varig. A propósito do Planejamento Político-Estratégico do MEC 1995/1998, ver Bueno (2000). servar esse compromisso assumido por nove países signatários da citada declaração, dentre eles o Brasil, sobre as mudanças na esfera educacional. ${ }^{3}$

Como acentua Corággio (1996), um dos possíveis sentidos das políticas sociais do Banco Mundial é:

\begin{abstract}
[...] instrumentalizar a política econômica, mais do que continuá-la ou compensá-la. São [as políticas sociais] o "Cavalo de Tróia" do mercado e do ajuste econômico no mundo da política e da solidariedade social. Seu principal objetivo é a reestruturação do governo, descentralizandoo ao mesmo tempo em que o reduz, deixando nas mãos da sociedade civil competitiva a alocação de recursos, sem a mediação estatal. Outro efeito importante é introjetar nas funções públicas os valores e critérios do mercado ( $a$ eficiência como critério básico, todos devem pagar pelo que recebem, os órgãos descentralizados devem concorrer pelos recursos públicos com base na eficiência da prestação de serviços segundo indicadores uniformes etc.), deixando como resíduo da solidariedade a beneficência pública (redes de seguro social) e preferencialmente privada, para os miseráveis. Em conseqüência, a elaboração das políticas setoriais [como as políticas públicas para a educação] fica subordinada às políticas de ajuste estrutural, e freqüentemente entra em contradição com os objetivos declarados. (p. 78-79, grifos meus)
\end{abstract}

Diante das transformações em curso, desde a década de 1970, no atual estágio de universalização do capitalismo, o capital pôs-se em territórios geográficos onde anteriormente não se movia, reorganizando socialmente as estruturas outrora organizadas segundo uma racionalidade de natureza diferente da sua, modificando dessa maneira o metabolismo social em nível planetário, impondo, por isso, um largo movimento de reformas institucionais. Em acréscimo, passou a organizar esferas sociais e políticas que se realizavam de

${ }^{3}$ Na nota 1, grifamos "sob o prisma de ajustes estruturais": isto é, os compromissos assumidos com as agências multilaterais, aqui com destaque para as de ordem financeira, devem realizar-se sob a orientação de um ajuste estrutural no país. 
acordo com diretrizes da lógica pública, determinando, dessa forma, novas relações entre o público e o privado, o que, articulado com o movimento geográfico, marca mudanças estruturais na reprodução da formação econômico-social capitalista. Isso acentua o movimento de reformas institucionais, em particular na esfera da educação.

A reforma educacional brasileira da segunda metade dos anos de 1990 é, ela mesma, na sua particularidade, parte das mudanças aludidas no parágrafo anterior e se estruturam segundo a mesma racionalidade dos movimentos referidos. Portanto, assistimos, nesse período, a uma série de transformações paradigmáticas na esfera educacional no Brasil. Ilustram essa afirmação a reforma curricular, realizada em todos os níveis e modalidades, de forma centralizada por especialistas de nossas melhores universidades, ${ }^{4}$ institutos e fundações de pesquisa, e a reforma no financiamento educacional articulado com a política avaliativa levada a termo pelo Sistema Nacional de Avaliação, dentre outras medidas no campo educacional (ver Silva Jr., 2002b). Tais medidas são os meios para a rearticulação das esferas pública e privada, que resultam dos deslocamentos do capital no processo de universalização do capitalismo.

Em meio à reforma educacional produzida no Núcleo Estratégico do Estado, destaca-se a sua dimensão docente, posto serem o professor e os dirigentes os agentes centrais de realização concreta da reforma e da mudança do paradigma educacional pretendido pelos gestores do MEC, por meio de suas práticas sociais no cotidiano da instituição escolar. Indaga-se, pois, quais são as tendências de formação dos professores, em particular no contexto desse movimento reformista da educação no Brasil. A julgar pelas diretrizes do Governo Fernando Henrique Cardoso, pela reforma do Estado e da educação ${ }^{5}$ e pelo que ex-

${ }^{4}$ Veja-se, por exemplo, o NUPES da Universidade de São Paulo, no que se refere à produção teórica para a reforma da educação superior (cf. Palharini, 1998).

${ }^{5}$ Ver as coletâneas organizadas por Morosini e Sguissardi (1998), Sguissardi (2000), Morosini (2001) e Sguissardi e Silva Jr. pusemos até aqui, pode-se ao menos levantar a hipótese de que as políticas de formação de professores tendem a seguir as orientações das mudanças sociais em geral, particularmente para a educação, com origem no Banco Mundial (cf. Torres, 1996, 1998; Brzezinski, 1999; Freitas, 1999; Kuenzer, 1999; Cunha, Lüdke \& Moreira, 1999; Libâneo \& Pimenta, 1999; Aguiar \& Sheibe, 1999). Com base em tal hipótese, indaga-se sobre as implicações teóricas, políticas e práticas de tais tendências, com foco na formação de professores a distância, tomando a atividade docente como uma prática social num contexto de mudanças nas estruturas sociais brasileiras, particularmente na educação, locus privilegiado de construção do ser social sob a intervenção do Estado reformado. A resposta para essa indagação é feita, nesse texto, pela análise dos três principais programas de educação a distância da Secretaria de Educação a Distância (SEED): o Programa Nacional de Informática na Educação, o TV Escola e, com foco especial, o Programa de Formação de Professores em Exercício, ${ }^{6}$ considerando-se a reforma do Estado e da educação no contex to do movimento de reformas em nível planetário para realizar a análise dessa modalidade de formação, com base na categoria de prática social tomada de Lukács (ver González \& Silva Jr., 2001).

\section{O s programas de educação a distância}

O Programa Nacional de Informática na Educação é desenvolvido em parceria com os governos de

(2001), todas publicadas com base nas pesquisas do Banco de Dados Universitas/BR, elaborado no âmbito do GT de Política de Educação Superior da ANPEd.

${ }^{6}$ Completam os cinco programas da SEED o Programa de Apoio em Educação a Distância e o Programa Rádio Escola, esse último articulado com o Programa de Alfabetização Solidária, que põe em movimento a transferência de responsabilidades do Estado para a sociedade civil, numa vertente privatista, que tem como resultado a mudança de um direito social (a educação) para um bem adquirido. 
estado e alguns municipais. "Seu principal objetivo é a introdução das Novas Tecnologias de Informação e Comunicação na escola pública, como ferramenta de apoio ao processo de ensino-aprendizagem. " ${ }^{\text {" Seria, }}$ segundo definição do MEC, portanto, "um programa de educação". Gostaria de destacar, se não uma indicação de identidade explícita entre uma "ferramenta de apoio" e um "um programa de educação", pelo menos uma afirmação que necessita de outras mediações para tornar-se consistente. Além disso, o "programa de educação" aqui indicado se reduz ao "processo de ensino-aprendizagem". Seu principal objetivo, como esteio da SEED, consistiria em "levar para toda a escola pública toda a contribuição que os métodos, técnicas e tecnologias de educação a distância podem prestar à construção de um novo paradigma para a educação brasileira" (grifos meus). Quanto à preparação dos recursos humanos, os agentes para a instituição do novo paradigma são os professores multiplicadores, especialistas que formariam os professores cursistas nas próprias escolas. Por sua vez, os professores multiplicadores seriam formados em cursos de pós-graduação lato sensu "ministrados por universidades brasileiras (públicas ou privadas, escolhidas em função da excelência na área do uso de tecnologia na educação)".

A SEED organiza-se, buscando estruturar um campo de formação de professores em exercício de forma centralizada, ainda que se apresente de forma descentralizada, produzindo uma aparência na qual as secretarias estaduais e municipais, bem como as escolas, pudessem usufruir de autonomia. ${ }^{8}$

${ }^{7}$ Disponível no site <http://www.mec.gov.br/seed>. Acesso em: 22 de setembro de 2002, do qual foram retirados todos os trechos entre aspas desse páragrafo.

${ }^{8}$ Em relação às suas metas, pode-se ler: "Para exercer as funções normativa, redistributiva, supletiva e coordenadora entre as instâncias educacionais, a Secretaria de Educação a Distância trabalha de forma articulada com os demais órgãos do Ministério da Educação e em conjunto com as Secretarias de Educação dos estados, municípios e Distrito Federal, com universidades, centros
Do que se escreveu até agora, pode-se levantar ao menos uma hipótese: qual seria a institucionalidade da educação a distância e da formação de professores? Há uma relação entre o Estado e a sociedade civil, o primeiro centralizando as funções de formulação e de avaliação, enquanto a execução é de pertença da segunda, produzindo, assim, um movimento que transfere deveres do Estado para a sociedade civil. O que implica em perda de direitos sociais do cidadão, uma vez que existe a indicação de um encurtamento da cidadania, realizado pelo Estado reformado. Por meio de quais instituições se realiza tal movimento?? Através de "universidades, centros de pesquisas, televisões e rádios educativas e outras instituições que utilizam a metodologia de educação a distância”. Isso supõe a reforma da educação superior, particularmente das universidades, institutos e fundações de pesquisa, bem como a mudança das atividades desenvolvidas pelos intelectuais dessas instituições ou organizações e a mudança de paradigma da ciência aí produzida. Além disso, há espaço para as organizações não-governamentais e para empresas que possam especializar-se nessas atividades, abrindo, dessa maneira, um nicho para o mercado, numa conjuntura em que o capital tem migrado extensiva e

de pesquisas, televisões e rádios educativas e outras instituições que utilizam a metodologia de educação a distância. Sua programação organiza-se em três blocos: a) desenvolvimento de projetos estratégicos; b) institucionalização da educação a distância no País; c) articulação do campo institucional e da sociedade civil" (grifos meus). Disponível em: <http://www.mec.gov/seed/ metas.htm>.

${ }^{9}$ Até julho de 2002, 13 universidades, uma confessional e as demais públicas, ofereciam a graduação em sua maioria licenciaturas, incluindo pedagogia em nível de graduação, enquanto seis instituições (três públicas e três privadas), até a mesma data, ofereciam cursos de pós-graduação lato sensu a distância. No segundo caso, é mais diversificado o campo temático dos cursos, encontrando-se desde cursos referentes à organização da produção, às ciências jurídicas e às ciências educacionais (disponível em: $<$ http://www.mec.gov/seed $>$ ). 
intensivamente para todos os espaços que outrora não eram organizados segundo sua racionalidade.

Acrescenta-se, segundo as linhas de ação da SEED no que se refere ao programa em pauta, o suposto da "existência de um sistema tecnológico - cada vez mais barato, acessível e de manuseio mais simples - capaz de", entre outras possibilidades, "familiarizar o cidadão com a tecnologia de seu cotidiano", "dar respostas flexíveis e personalizadas para as pessoas que exigem diversidade maior de tipos de educação, informação e treinamento" e "oferecer meios de atualizar rapidamente o conhecimento". ${ }^{10}$ Tais linhas de ação parecem demonstrar o critério norteador das escolhas de políticas de formação e capacitação de professores: o uso intensivo de novas tecnologias educacionais e, talvez, a relação custo/benefício como definidora do tipo de exercício dessas atividades formativas. Trata-se, pois, de uma institucionalidade na qual predomina o privado, tanto no que se refere ao que não é de alçada do Estado quanto no que se refere à esfera econômica e à racionalidade mercantil. Constitui-se, em potência, um campo formativo de professores orientado pela racionalidade do mercado a produzir uma esfera política, na qual o campo profissional torna-se o centro. $\mathrm{O}$ que é um indicativo de que a valorização dos professores se daria por meio de sua capacitação instrumental e não pelo papel essencial que ele exerce na construção das relações sociais e na formação humana. Isso pode explicar, ao menos parcialmente, o fato de as reformas educacionais estarem orientadas por pedagogias do aprender a aprender (cf. Duarte, 2001) ou pelo modelo de competências, nos quais "A riqueza do contexto do trabalho para dar significado às aprendizagens da escola média é incomensurável. Desde logo na experiência da própria aprendizagem como um trabalho de constituição de conhecimentos, dando à vida escolar um significado de maior protagonismo e responsabilidade", como se pode ler nas bases legais das Diretrizes

${ }^{10}$ Disponível no site : <http://www.mec.gov.br/seedem>. Acesso em: 22 de setembro de 2002 .
Curriculares Nacionais para o Ensino Médio ${ }^{11}$, por exemplo.

O Programa TV Escola é o núcleo forte do Programa Nacional de Informática na Educação e expressa em sua concretização as orientações da SEED. É “dirigido à capacitação, atualização e aperfeiçoamento de professores de Ensino Fundamental e Ensino Médio da rede pública", além de ser uma "das ações prioritárias da Secretaria de Educação a Distância". ${ }^{12}$ Destaca-se, ainda, que o TV Escola é parte do Planejamento Político Estratégico, tido como a atualização do Plano Decenal de Educação para Todos. Enquanto o segundo foi o resultado da produção de um consenso para pôr em ação no Brasil o movimento reformista educacional de nível planetário, o primeiro consiste nas bases e orientações da reforma e foi produzido com assessoria de agências multilaterais e universidades norte-americanas, ${ }^{13}$ que induziram, inclusive, o arcabouço jurídico educacional brasileiro.

No "breve histórico" do programa TV Escola encontra-se referência quanto à relação entre o Plano Decenal de Educação para Todos e o Planejamento Político Estratégico do Ministério da Educação 1995/1998:

A TV Escola atende, também, aos objetivos gerais de desenvolvimento da educação básica estabelecidos pelo Plano Decenal, que determinou, dentre outros, assegurar "a todas as unidades de ensino padrões básicos de provisão de ambiente físico, de recursos e tecnologias instrucionais [...]" e enriquecer "o acervo de recursos e tecnologias de apoio à escola e aos professores e dirigentes". (Disponível em: <http://www.mec.gov.br/seed>. Acesso em: 22 de setembro de 2002)

${ }^{11}$ Disponível em: 〈http://www.mec.gov.br>. Acesso em: 13 de julho de 2002.

${ }^{12}$ Disponível em: <http://www.mec.gov.br/seed>. Acesso em: 22 de setetembro de 2002 .

${ }^{13}$ A Oklahoma State University prestou assessoria na formulação dos Parâmetros Curriculares Nacionais, segundo Bueno (2000). 
O programa atende ao ensino fundamental e ao ensino médio, e em ambos os níveis suas orientações ancoram-se nas Diretrizes Curriculares Nacionais e nos Parâmetros Curriculares Nacionais, com foco no processo de ensino e aprendizagem. A TV Escola conta também com o programa Salto para o Futuro como ferramenta para a formação continuada para os professores em exercício. Para isso, utiliza-se de diversificados tipos de tecnologias de comunicação e informação - televisão, internet, fax, telefone e material impresso - no debate de questões relacionadas à prática pedagógica. O programa conta com orientadores educacionais em 800 telepostos distribuídos em todo o território nacional. ${ }^{14}$

A SEED e seus programas de educação a distância procuram produzir um novo paradigma para a educação brasileira por meio da institucionalização dessa modalidade educacional, que, dentre outras características, põe-se como porta de entrada do capital industrial nessa esfera. Uma evidência dessa afirmação é o kit tecnológico do TV Escola.

O universo da TV Escola são escolas públicas com mais de 100 alunos e com energia elétrica, conforme o que estabelece a Resolução FNDE n 21, de 07 de agosto de 1995, independente de localização urbana ou rural. A infra-estrutura repassada a essas escolas foi um conjunto de equipamentos, denominado "kit tecnológico", composto por: televisor, videocassete, antena parabólica, receptor de satélite e dez fitas de vídeo VHS. Em algumas regiões, foi autorizada a compra de um estabilizador de voltagem. Até 2000, os kits foram adquiridos de forma descentralizada, com recursos do Fundo Nacional de Desenvolvimento da Educação (FNDE), repassado às Secretarias Estaduais ou Municipais de Educação para atendimento das escolas de ensino fundamental e médio. Até 1999, 57.935 kits haviam sido adquiridos. ${ }^{15}$

${ }^{14}$ Observo aqui o significativo papel dos pesquisadores, pertencentes na sua maioria às nossas universidades, na produção dos programas televisivos do Salto para o Futuro, para a consecução de seus fins.

${ }^{15}$ Disponível em: 〈http://www.mec.gov.br/seed/kittecnologico/〉.
Como se pode observar, a possibilidade de migração do capital industrial para a esfera educacional é bastante larga, quando se observa tão somente o kit tecnológico. No entanto, para além da racionalidade carregada com ele, de natureza privada, no plano econômico, as práticas sociais também são orientadas por essa mesma racionalidade, no que toca aos valores que orientam essa mesma prática social dos professores, condicionando, assim, a formação orientada pelos valores mercantis, o que põe o campo profissional em evidência para o docente e seus alunos. No âmbito pedagógico, as novas tecnologias educacionais trazem consigo a limitação de opções para a formação, além de tornar rígido o campo de ação dos professores multiplicadores e, consequentemente, mais rígida a ação dos professores cursistas. A base tecnológica orienta o campo de alternativas da prática formativa ancorada nas relações sociais. Quando a prática se realiza de forma presencial, o campo de alternativas se faz na relação entre a objetividade social compartilhada pelos atores das práticas sociais na instituição escolar. Através da educação a distância torna-se impossível a transferência da objetividade social entre os especialistas e os professores em formação no exercício da profissão. Essa parece ser uma das razões para as reformas estarem embasadas no império do cognitivismo, da adaptação e da instrumentalidade, como mostram os pressupostos da reforma educacional da segunda metade dos anos de 1990.

O Programa de Formação de Professores em Exercício (Proformação) orienta-se pelos dois programas anteriormente apresentados e a eles se articula. Caracteriza-se como um curso de magistério de nível médio, "dirigido aos professores que, sem a formação específica, encontram-se lecionando nas quatro séries iniciais do ensino fundamental e nas classes de alfabetização das redes públicas das regiões Norte, Nordeste e Centro-Oeste". ${ }^{16}$ Segundo o "histórico" do Proformação, sua conexão com o Fundo de Ma-

${ }^{16}$ Disponível em: 〈http://www.mec.gov.br/seed>. Acesso em: 22 de setembro de 2002 . 
nutenção e Desenvolvimento do Ensino Fundamental e de Valorização do Magistério (FUNDEF) teria gerado a necessidade de habilitação dos professores sem a formação mínima exigida por lei, requerendo da parte dos dirigentes iniciativas no sentido do cumprimento deste dispositivo. Em decorrência:

A direção da União Nacional dos Dirigentes de Educação (UNDIME) e o Conselho Nacional dos Secretários de Educação (CONSED), na busca de parceiros, identificam na Secretaria de Educação a Distância (SEED) o apoio necessário à implantação de um programa adequado à formação dos professores em exercício, que pudesse ser implementado dentro dos princípios de qualidade. (Disponível em: <http://www.mec.gov.br/seed/>)

É necessário destacar alguns elementos do que se expôs até o momento sobre o Proformação: 1) o FUNDEF é chamado para explicar a necessidade de uma formação mínima dos professores aos quais o programa se destina; e 2) os atores, com base no argumento exposto no item 1, elegem a SEED como parceira fundamental para levar a termo o que exige a lei $\mathrm{n}^{\circ}$ 9.394/96. Retomo o argumento aqui discutido sobre a natureza do Plano Decenal de Educação para Todos e do Planejamento Político-Estratégico do Ministério da Educação 1995/1998, e das relações que se estabelecem entre eles, para argumentar, como Davies (2001), que o FUNDEF consiste num bom instrumento administrativo financeiro para redistribuir as verbas da educação entre as três instâncias do Estado, transformando o papel da União de provedor e avaliador para formulador e avaliador. Observo, também, que os atores que firmaram o Compromisso de Educação para Todos durante a Semana Nacional de Educação para Todos (ver nota 2) são basicamente os mesmos que elegem a SEED como parceira para reiterar a formação mínima com o argumento-força das necessidades geradas pela implantação do FUNDEF. A articulação entre os pressupostos e os instrumentos administrativos e jurídicos da reforma educacional iniciada nos anos 1990 é extremamente coerente. A construção do consenso para a sua realização é igualmente eficien- te e se manteve por um longo prazo, como nos mostram os produtores do "Compromisso de Educação para Todos". A ligação com os organismos multilaterais põe-se em evidência em 1993, como aparece no histórico do Programa de Formação de Professores em Exercício - evidências da relação orgânica entre nossas reformas e as reformas educacionais em curso no mundo. Lê-se nesse item:

A partir de 1996, várias reuniões são realizadas com a direção da UNDIME e do CONSED. Os Secretários Estaduais de Educação designam um representante [...] para formulação da proposta pedagógica e elaboração de acordos que serviram de base de negociação do programa. Ainda no ano de 1996, a SEED inclui em seu programa de trabalho a meta - formação em nível médio dos professores em exercício nas séries iniciais das escolas públicas de educação fundamental, com previsão de recursos no componente nacional do Projeto Nordeste. Mas foi somente ao final do ano de 1997, com sua inclusão no FUNDESCOLA que foram dados os passos mais consistentes no sentido de sua viabilização, com iniciativas concretas por meio da constituição do Grupo de Trabalho e com a conseqüente contratação de consultoria pedagógica para a coordenação do processo de formulação da concepção pedagógica e a definição de mecanismos operacionais à sua implantação. Em fevereiro do ano de 1998, em João Pessoa - Paraíba, por ocasião do Workshop Precursor do Programa de Formação de Professores, representantes das Secretarias de Educação e das Universidades Federais dos 19 estados compreendidos no FUNDESCOLA, representantes da UNDIME em âmbito Nacional e Estadual, principalmente das regiões Norte, Nordeste e Centro-Oeste, e representantes da UNESCO participaram da discussão da proposta pedagógica e operacional, com indicações de ações visando sua implantação no início do ano de 1999. A partir de junho de 1998, foram contratadas equipes de especialistas nas áreas temáticas e em produção de vídeos para a elaboração dos materiais didáticos guias de Estudos e vídeos, obedecendo critério seletivo. (Disponível em: <http://www.mec.gov.br/seed>)

A Lei n ${ }^{\circ} 9.394 / 96$ é a principal sustentação jurídica da reforma educacional brasileira dos anos de 
1990, em relação aos níveis básico e superior. Basta analisarmos a base legal do Proformação (disponível em: <http://www.mec.gov.br/seed>), na qual se encontra a atribuição aos municípios e, "supletivamente, ao Estado e à União", da formação, com base no art. 87, parágrafo $3^{\circ}$, inciso III, que consiste na incumbência de "realizar programas de formação para todos os professores em exercício, utilizando para isso também os recursos da educação a distância". Além disso, a lei $n^{\circ}$ 9.424/96, que dispõe sobre o FUNDEF, também dá guarida à base legal do Proformação. Ela sustenta que a citada lei estabelece tempo de cinco anos para a formação e "prevê meios para isso, permitindo que parte dos recursos financeiros destinados à remuneração dos profissionais do Magistério seja investida na capacitação de professores leigos [...] no ensino fundamental". A valorização do magistério (um dos objetivos do FUNDEF) é aqui entendida, de um lado, reduzidamente na sua dimensão profissional, e, de outro, evidencia, mais uma vez, as tendências da formação sob orientação dos organismos multilaterais.

Torres, analisando as tendências da formação docente e de professores com base nas orientações do Banco Mundial, escreve, quanto à relação dicotômica professores e tecnologia educativa, que a opção é sempre pela última, buscando nela "não só um apoio ao educador, mas um substituto e uma 'solução' para o problema docente", tais como "baixos salários, deficiente formação, escasso tempo disponível, etc.” (1996, p. 174). Por constituir-se em uma orientação de um banco (Banco Mundial), as tensões que são intrínsecas à formação docente em geral e dos professores em particular são analisadas como dicotomias e, portanto, constituídas por pólos excludentes. As políticas que são formuladas com base em tal suposto devem orientar-se por um ou outro pólo, com base em algum critério. Tratando-se de um banco, ainda que com grande interferência na área social, o Banco Mundial tem como critério a eficiência, a eficácia, a produtividade a razão mercantil -, o que implica dizer que o critério fundamental é a razão de proporcionalidade custo/benefício, sem a preocupação do educador com a for- mação voltada para a elevação da condição humana. Se tratadas como são, as tensões poderiam contemplar as relações entre formação inicial e em serviço, professor e tecnologia educativa etc.

Diante do que se expôs, que racionalidade informa as políticas públicas para a formação de professores por meio da educação a distância, diante do Estado e da educação reformados, num contexto de universalização do capitalismo e de sua conseqüente mudança no metabolismo social, nas palavras de István Mézáros?

\section{A reforma do Estado e da educação no Brasil e a educação a distância: os desafios políticos ${ }^{17}$}

A resposta, ainda que provisória, a essa indagação deve considerar as mudanças em curso no Brasil, especialmente a partir do início dos anos de 1990, as quais trataremos, ainda que de forma breve, para a análise do seu objeto e de suas hipóteses. Isso impõe a necessidade de buscarmos as relações entre a reforma do Estado e da educação brasileira e as políticas de formação de professores por meio da educação a distância, para, então, podermos comentar as implicações políticas dessa modalidade de formação de professores.

A análise feita por Popkewtiz (1997) sobre a reforma educacional dos anos 1980, tomando por base as continuidades e simultâneas rupturas ocorridas em relação às dos anos 1960, nos Estados Unidos, nos ajuda a entender melhor a reforma da educação nos anos de 1990 na América Latina, mas especialmente no Brasil, por várias razões. O movimento reformista

\footnotetext{
${ }^{17}$ As análises e reflexões que articulo nesta seção são resul-
} tado das pesquisas e discussões que tenho realizado, há dez anos, com Valdemar Sguissardi. Sua síntese, considerando o contexto de sua publicação, é o livro Novas faces da educação superior no Brasil - reforma do Estado e mudanças na produção (Cortez e EDUSF, $2^{a}$ edição em 2001). Isso explica semelhanças na redação; a conclusão, porém, já se põe em outro patamar, incorporando o acúmulo do trabalho por nós já realizado. 
educacional dos anos 1980, visto na perspectiva dos Estados Unidos e segundo Popkewitz, deve ser compreendido com base em três dinâmicas:

\section{A ênfase na ciência rigorosa e neutra como meio} para a realização da utopia lúdica do futuro próspero e feliz, bem como a profissionalização como categoria epistemológica e política, constituem-se em traços tácitos das reformas da década de 1960.

2. Diante da universalização do capitalismo, da posição e do papel dos Estados Unidos nesse processo, a ciência, além de profissionalizada, torna-se agora mercadoria, e a profissionalização torna-se o epicentro do atual paradigma político, tendo no individualismo possessivo, ${ }^{18} \mathrm{seu}$ principal traço e valor.

3. Na década de 1960 havia uma crença na ciência e na profissionalização voltada para o social e para a construção de um mundo feliz e próspero. Na década de 1980, com o movimento de reformas, orquestrado especialmente nas universidades por seus intelectuais, essa utopia cede lugar, diante dos deslocamentos do capital, a uma base valorativa assentada na busca da eficiência, na eficácia e no consenso para o alcance da excelência segundo os valores mercantis, centrados no individualismo possessivo.

Em relação às reformas dos anos de 1980 nos países com economia central no plano mundial, e nos

${ }^{18}$ Tal valor faz com que o indivíduo passe a enxergar sua forma de ser como natural, movimento semelhante ao que identificou, em certa medida, as ciências sociais às ciências físicas e naturais. "A inteligência, o caráter, o desempenho e a moralidade são tratados como 'fatos objetivos' que podem ser identificados e medidos independente da relação do indivíduo com a comunidade [...]", o que implica dizer que "possuir uma qualidade significa ser seu dono, como se é de uma propriedade ou de um bem.” A isso Macpherson chamou de individualismo possessivo (cf. Popkewitz, 1997, p. 153). anos de 1990 no Brasil, é necessário observar os seguintes eventos: 1) a universalização do capitalismo, particularmente por meio do capital produtivo macrogerido pelo financeiro, impôs profundas mudanças no metabolismo social do mundo todo (Mézáros, 2002 , p. $133-1740) ;{ }^{19}$ 2) a profunda mudança no metabolismo social impôs um novo processo de reprodução social, que, por sua vez, implicou alterações nas estruturas sociais; e 3) isso pôs em movimento reformas institucionais em várias áreas da atividade humana nesse modo de produção, mas principalmente na esfera educacional. Portanto, o movimento reformista em geral, especialmente para a educação, não é um movimento que deva ser estudado de forma destacada das mudanças apontadas, menos ainda ser pensado como um fato de um único país; trata-se de um movimento mundial, com as especificidades históricas de cada um, mas que mantém traços de identidade em todos eles, segundo a racionalidade da transição do metabolismo social capitalista.

Destaco, ainda, o papel que a reforma da educação superior teve no Brasil, a exemplo dos outros países, na reconfiguração da esfera social da educação, no contexto já indicado, e no redimensionamento operado pelos intelectuais nos espaços públicos e privados. Basta olharmos os formuladores das reformas em geral, desde o Estado até os instrumentos de avaliação das escolas públicas e de projetos sociais assistencialistas. Quando tomamos as reformas educacionais nos vários níveis e modalidades de ensino, bem como os processos oficiais de avaliação e financiamento, observamos que os formuladores dos documentos que orientam a reforma, desde a educação infantil até a pós-graduação e a indução da pesquisa, são em sua maioria especialistas ou pesquisadores dessas áreas. Isso indica as continuidades na reforma da educação brasileira em relação às dos demais países, apontando como a reforma da educação, ancorada na mudança do papel da ciência e dos intelectuais, busca consolidar um "novo paradigma educacional"

\footnotetext{
${ }^{19}$ Ver Silva Jr. (2002c).
} 
e um "novo paradigma para a ciência e a pesquisa", por meio da mudança do campo profissional - tendo por campo teórico orientador as pedagogias do aprender a aprender a noção de competências e empregabilidade (Silva Jr., 2002a). Contribuindo, dessa forma, para uma mudança no paradigma político no Brasil a partir dos anos 1990. O Brasil, por razões específicas (Oliveira, 1992), acentua seu ajuste estrutural, inserindo-se na Nova Ordem Mundial apenas na década de 1990. Com a legitimidade política e eleitoral, e em um clima de hiperpresidencialismo, o presidente Fernando Henrique Cardoso transforma o Brasil no país das reformas e o submete, apesar de suas peculiaridades, ao figurino do capital, desenhado, agora, pelos organismos multilaterais, com especial destaque para o Banco Mundial.

As reformas do Estado no atual estágio do capitalismo mundial tendem para um desmonte do Estado intervencionista na economia e nos setores sociais. A universalização do capitalismo e a divisão planetária em megablocos econômicos impõem uma reforma dos Estados que propicie a expansão do mercado e de sua lógica, sob o discurso da auto-regulação, bem como possibilita, como acentua Corággio (1996), a introjeção da racionalidade mercantil na esfera pública, como se pode depreender das propostas de reforma administrativa do ex-ministro Bresser Pereira. Dessa forma, na transição do fordismo para o presente momento histórico do capitalismo mundial, o Estado de bem-estar social dá lugar a um Estado gestor, que carrega em si a racionalidade empresarial das corporações transnacionais, tornando-se, agora, as teorias organizacionais, antes restritas aos muros das fábricas, as verdadeiras teorias políticas do Estado moderno. A inserção do Brasil nesse processo provoca também uma transformação no aparelho de Estado, que de interventor e estruturador da economia em favor do capital nacional e internacional, desde a década de 1930, passa na década de 1990 a um Estado modernizado, a um Estado gestor voltado para a reprodução do capital e de elaboração de políticas sociais a serem desenvolvidas no âmbito da sociedade civil, ainda que sob seu controle e avaliação.
Bresser Pereira (1996), ${ }^{20}$ em Crise econômica e reforma do Estado no Brasil. Para uma nova interpretação da América Latina, oferece um quadro mais detalhado de sua concepção do Estado, dividindo-o em quatro setores, buscando produzir uma estrutura para a administração pública gerencial, isto é, orientada pelos valores do privado. E, fazendo eco a um movimento nos meios de comunicação - que, em geral, tem desqualificado os serviços públicos ou de responsabilidade coletiva por oposição ao privado e individual -, o autor enfatiza as qualidades do setor privado ao propor que a eficiência, agilidade etc. dos serviços do Estado deveriam ser semelhantes às desse setor. Para chegar-se a esse nível de eficiência e agilidade, defende a adoção de uma forma de organização administrativa mais flexível do que a adotada no núcleo burocrático da administração direta, que se apoiaria especialmente nas denominadas "organizações sociais" congêneres das organizações nãogovernamentais, no âmbito do Estado. Além das organizações sociais, Bresser Pereira propõe a criação de agências executivas e profissionalização dos servidores (do núcleo estratégico do Estado).

O grande obstáculo para os projetos de reforma propostos seria a rigidez burocrática imposta pela Constituição de 1988. Daí a necessidade de sua urgente reforma, para maior flexibilização da administração (maior eficiência e qualidade) e mudança do sistema de previdência do funcionalismo (menor custo e maior isonomia com o setor privado). Foram propostas medidas para tornar a previdência dos funcionários menos onerosa e mais semelhante à vigente no setor privado (cf. Bresser Pereira, 1996, p. 11-12). O programa de transformação das entidades de serviços do Estado em "organizações sociais" foi denominado de "Programa de Publicização". Essas novas entidades administrativas de serviços públicos seriam "entidades públicas nãoestatais" ou "fundações públicas de direito privado".

${ }^{20}$ Observo uma curiosidade em relação a esse livro: foi primeiramente escrito em inglês e publicado nos Estados Unidos, depois traduzido para o português e publicado no Brasil, em 1996. 
Para conduzir as "organizações sociais" à dita "publicização" dos serviços públicos, dois projetos são considerados essenciais:

[...] descentralização dos serviços sociais do Estado, de um lado para os Estados e Municípios, de outro, do aparelho do Estado propriamente dito para o setor público não estatal. Esta última reforma se dará através da dramática concessão de autonomia financeira e administrativa às entidades de serviço do Estado, particularmente de serviço social, como as universidades, as escolas técnicas, os hospitais, os museus, os centros de pesquisa, e o próprio sistema de previdência. Para isso, a idéia é de criar a possibilidade dessas entidades serem transformadas em "organizações sociais".

Organizações sociais serão organizações públicas nãoestatais - mais especificamente fundações de direito privado - que têm autorização legislativa para celebrar contrato de gestão com o poder executivo, e assim poder, através do órgão do executivo correspondente, fazer parte do orçamento público federal, estadual ou municipal. (Bresser Pereira, 1996, p. 13)

Para Bresser Pereira, isso permitiria a essas instituições ampla autonomia na gestão de suas receitas e despesas, pois continuariam a contar com a garantia básica do Estado que lhes cederia, por mútuo, seus bens e seus funcionários estatutários. Agora, porém, se trata de entidades de direito privado, que escapam "às normas e regulamentos do aparelho estatal, e particularmente de seu núcleo burocrático..." (1996, p.13).

Na oportunidade do anúncio dessas idéias e propostas básicas de reforma do aparelho do Estado, especialmente referindo-se às organizações sociais, Bresser Pereira (1996) preocupa-se com a necessidade de evitar-se "a privatização e a feudalização" dessas entidades, ou seja, "a apropriação destas por grupos de indivíduos que as usam como se fossem privadas", e alerta para a necessidade de serem criadas "cautelas legais e administrativas", "tomando-se, entretanto, o cuidado de limitar os controles por processo, já que o essencial será, tanto da parte do pró- prio Estado, quanto da sociedade, o controle por resultados das organizações sociais" (p. 13). Dessa forma, a matriz orientadora da reforma do Estado traduz-se na reforma da educação brasileira para a produção da reforma nos diversos níveis de ensino e modalidades educacionais, sendo esse movimento reformista, por uma ciência que se tornou mercadoria e por uma profissionalização que, cientificizada, tornou-se centro do paradigma político atual. Dito de outra forma, o campo profissional passa a ser a esfera de mediação entre o Estado e a sociedade civil e entre o indivíduo e a sociedade. Daí, talvez, a proeminência, como pressupostos da reforma educacional, das pedagogias do aprender a aprender e da noção de competências: a exclusividade do cognitivo na formação humana em detrimento da educação tomada como prática social. Isso possibilita as características dos programas da SEED e sua institucionalidade pretendida.

As políticas de formação de professores através da educação a distância parecem seguir a mesma racionalidade da matriz teórica, ideológica e política da reforma do Estado e da educação no Brasil. A institucionalidade da educação a distância e a racionalidade política, tal qual ocorre na reforma do Estado e na reforma educacional, que a informam, pode ser sintetizada da seguinte maneira: 1) as relações entre Estado e sociedade civil alteram-se, impondo para essa segunda esfera, no campo social, responsabilidades outrora de pertença do Estado; 2) este último passa a formular as políticas no seu núcleo estratégico e a avaliar a execução no âmbito da sociedade civil, contingenciando o financiamento das ações desenvolvidas por instituições, organizações não-governamentais ou mesmo empresas do terceiro setor; 3) as principais instituições são as universidades ou outras instituições da educação superior com excelência em educação tecnológica e tecnologias educativas; 4) esse novo complexo de relações entre o Estado e a sociedade civil produz uma grande potência para a privatização, seja no que se refere à transferência de responsabilidades para a sociedade civil, seja em relação ao âmbito econômico, na medida em que possibilita um grande nicho de mercado para em- 
presas de consultoria, por um lado, e de outro, tornase a porta de entrada para o capital industrial, como se ilustrou com o necessário kit tecnológico do TV Escola mais os custos de transmissão; 5) supõe a existência de um sistema tecnológico barato e acessível, o que implica indicar um critério que merece atenção: a razão de proporcionalidade custo/benefício do investimento na formação de professores através da educação a distância; e 6) o que orienta os programas analisados são os Parâmetros Curriculares Nacionais e as Diretrizes Curriculares, o que, talvez, nos ajude a entender algumas linhas de ação propostas, tais como "familiarizar o cidadão com a tecnologia de seu cotidiano" (sem questionar a razão de sua existência), "dar respostas flexíveis e personalizadas para as pessoas que exigem diversidade maior de tipos de educação (reduzida ao processo de ensino-aprendizagem), informação e treinamento" e "oferecer meios de atualizar rapidamente o conhecimento." ${ }^{21}$ Tais linhas de ação fazem supor um processo educacional baseado predominantemente no cognitivo e no gnosiológico, sem a preocupação em ver a educação como uma prática social. Em acréscimo, elas sugerem a adaptação e a instrumentalidade como pilares da formação dos professores.

Diante da institucionalidade da educação a distância, produzida como decorrência da análise dos programas da SEED, articulada com a análise da reforma do Estado e da educação brasileira, com destaque para a educação superior e o novo paradigma de ciência em grande parte aí produzida, é possível dizer, como se lê no Programa Nacional de Informática na Educação, que o objetivo da SEED constitui-se em pôr-se como mediadora na formação dos professores, para a produção de um "novo paradigma educacional" alinhado às mudanças em curso no âmbito político. Ao estudarmos a especificidade dos programas dessa modalidade educacional, apanhamos, ao mesmo tempo, a racionalidade que informa as trans-

${ }^{21}$ Disponível em: <http://www.mec.gov.br/seed>. Acesso em: 24 de setembro de 2002. formações por que passou o Brasil nos últimos vinte anos, que tem em seu centro as reformas institucionais nas diferentes esferas de atividade humana com o objetivo político estratégico de mudança nas estruturas sociais brasileiras, dada uma inserção submissa no processo de universalização do capital em nível planetário. Diante do que se expôs, indaga-se agora: quais as implicações teóricas da formação de professores por meio da educação a distância?

\section{Educação como prática social e a educação a distância: os desafios teóricos}

A educaçãoé uma esfera social de formação humana e, como tal, realiza-se no âmbito das relações sociais, pondo-as em movimento, concretizando-as por meio da prática humana na especificidade da esfera educativa. Essa esfera também tem sua dimensão política e se constitui como um campo de luta ideológica, isto é, um campo de disputa hegemônica, ainda que aí predominem as orientações com origem no Estado. A análise feita mostrou que as reformas, e particularmente a formação de professores, parecem enfatizar uma pseudoformação articulada com uma submissão política do Brasil aos organismos multilaterais. Agora interessa-nos compreender as implicações teóricas das atividades formativas a distância, e para isso tomaremos a categoria de prática social em Marx, que tem uma formulação mais precisa na Ontologia do ser social de Lukács (1983, 1990). Esse autor põe-se como objetivo o entendimento da socialização do ser humano na sua reprodução singular, através da prática social na cotidianeidade. Para tanto, considera que as práticas sociais, no seu conjunto, realizam a reprodução social da vida humana, por meio de múltiplos processos mediados, tendo - em última instância - o trabalho simples como elemento que funda essas práticas.

Lukács $(1983,1990)$ busca mostrar, além da generalidade do homem produzida pelo trabalho, que a intensificação da sociabilidade humana também fazse por meio da prática social. Para o autor, o indivíduo mantém na sua prática a substância histórica do seu ser, e a totalidade social consistiria em um movi- 
mento sintético das alternativas escolhidas nos momentos da realização da prática dos indivíduos na sua singularidade ou na sua particularidade. Para ele, o homem se define e se forma na atividade mais comezinha e cotidiana.

Em toda a prática humana há a precedência de uma tensão entre o subjetivo e o objetivo; o ser humano põe-se uma meta para realizá-la por meio da prática, e já no primeiro momento dessa atividade humana tem de considerar todo espectro de possibilidades existentes no contexto social e natural em que se insere, para poder escolher a referida meta, objetivando sua própria reprodução. Essa meta posta é produto daquela tensão. No entanto, para atingi-la, deverá escolher um meio, dentre muitos. Para realizar a meta produzida no primeiro momento, terá que escolher uma alternativa de saberes sobre o mundo, particularmente sobre o contexto em que ele e sua meta se inserem. Nesse segundo momento de sua prática social, portanto, o sujeito deverá por em ação sua dimensão cognitiva, seus saberes, na busca de uma entre várias alternativas existentes, que podem ou não consumar sua meta, quando nova tensão entre o subjetivo e o objetivo se lhe põe. Nesse momento, ainda que tais tensões encontrem-se na condição de potência daquela prática no âmbito da consciência, já expressa a objetividade social e a natureza, na forma gnosiológica ou cognitiva, isto é, no plano teórico.

As tensões produzidas nos dois momentos precedentes mobilizam o ser social em direção à meta escolhida, por meio de uma alternativa eleita no segundo momento do plano teórico como referido acima. Isso é realizado pelo ser social por meio do saber acumulado sobre o mundo objetivo que ele possui, para a realização da prática. Trata-se da objetivação do que era potência no plano da consciência. A objetivação da potência é, portanto, movimento contínuo e contraditório entre subjetivo e objetivo, num processo de infinitas mediações entre a potência (a objetividade social posta no âmbito da consciência nos dois primeiros momentos já indicados) e a objetividade social. O homem através da objetivação busca atingir a meta posta e realiza-se em condições objetivas determinadas, que se expressam em sua consciência e a formam. Assim, o ser humano afirma sua condição, experimentando a liberdade no ato das escolhas, porém, num horizonte de possibilidades determinada pela objetividade social e a natureza.

Consumada sua meta, o homem singular transforma seu ser social, e o resultado de sua prática social põe em movimento novos fatos sociais, transformando a objetividade, que lhe apresenta novas necessidades, novas possibilidades de liberdade e de determinações, novas relações entre o objetivo e o subjetivo. Não consumada sua meta, as tensões entre o subjetivo e o objetivo permanecem em potência tal qual nos dois primeiros momentos, não havendo, portanto, complexificação da sociabilidade humana do sujeito da prática, tampouco alterações qualitativas no curso do movimento da objetividade social ou da natureza. Disso decorre que tão-somente os aspectos cognitivos, ainda que imprescindíveis na prática social, como acentuado anteriormente, de um lado, não têm a força para a constituição do ser social (posto não ter havido uma elevação da complexidade de seu ser social), de outro, não transforma a realidade social objetiva. Posto isso, duas questões emergem: 1) a prática social formativa entre sujeitos diferentes somente realiza-se se a meta posta no curso da prática social consumarse; e 2) a prática social formativa entre sujeitos diferentes contrária à pseudoformação deve realizar-se sob as mesmas condições sociais e naturais. Do que decorre a impotência da educação a distância vir a ser um meio privilegiado para um "novo paradigma educacional", que eleve a condição humana. A prática escolar deve ser presencial se o objetivo for não somente a instrumentalização do ser humano, mas a elevação de sua condição de ser.

A prática social formativa deve pois realizar a meta posta pelo sujeito no mesmo horizonte de possibilidades de seu objeto ou de outros sujeitos que participem da mesma prática de forma direta. Não consumada a meta, o resultado consiste em maior acúmulo do saber sobre os meios para a realização do objetivo determinado pelo sujeito. Esse constructo teórico, ainda que hermético, possibilita refletir sobre as consequiên- 
cias teóricas decorrentes das pedagogias assentadas em teorias cognitivas, como as do aprender a aprender ou a noção de competências (que dão sustentação para os programas de educação a distância) a partir dessa perspectiva da prática educativa. Poderíamos então afirmar que o alcance de tais teorias será sempre o de se aproximar da realidade social por meio exclusivo do plano teórico e no que ela tem de aparente, para colocar-se objetivos também nesse mesmo plano, isto é, o da aparência. As escolhas de alternativas se darão no horizonte de possibilidades dessa mesma aparência, fazendo com que o indivíduo se forme e atue no mesmo âmbito, o que implica sempre sua adaptação e sua instrumentalização para o enfrentamento de problemas nesse plano da objetividade social. Mesmo aí, uma prática formativa entre diferentes sujeitos precisa realizar-se no mesmo espaço e tempo das relações sociais em que desenvolvem suas práticas sociais educativas, escolares ou não.

A educação a distância põe-se como uma prática instrucional entre diferentes sujeitos, mediada por tecnologias de informação e comunicação com foco no processo de ensino-aprendizagem, num contexto tal em que a objetividade social apresenta um horizonte de possibilidades orientado pela racionalidade mercantil produzida pela mudança nas estruturas sociais, resultado do processo de reformas que se assistiu no país na segunda metade da década de 1990, especialmente as do Estado e as da educação. Em acréscimo, a mediação feita através do "barato e acessível sistema tecnológico", quando utilizado como instrumento dessa modalidade educacional, reduz as possibilidades dos sujeitos da prática educativa com foco no cognitivo de desenvolverem-na nas mesmas condições sociais. Torna as ações instrucionais a distância instrumentos para uma adaptação do sujeito a sua própria realidade, sem darlhe a oportunidade de formar-se para além dos "saberes" (do cognitivo), na troca que se estabelece na prática social no que se refere aos desejos, sentimentos e valores. Isto é, no processo de ensino-aprendizagem, o sujeito parece ser colocado em plano secundário, numa posição passiva, sem que tenha a oportunidade de enfrentar o conflito, a contradição e a tensão, intrínsecos a qualquer processo formativo. Os Parâmetros Curriculares Nacionais lhe são efetivamente impostos como a referência de especialistas, mediada, por processos tecnológicos. Do que depreendemos, no que toca às implicações teóricas da educação a distância, que ela se configura como uma forma de auxiliar a formação de professores em exercício, mas jamais poderá ser a única maneira de fazê-lo.

JOÃO DOS REIS SILVA JÚNIOR, doutor em educação pela PUC/SP, com pós-doutoramento em sociologia política pela UNICAMP, atualmente é professor e pesquisador nos Programas de Pós-graduação em Educação da PUC/SP: História, Política e Sociedade e da Universidade de Sorocaba. É autor de vários artigos e capítulos de livro no Brasil e no exterior. Seus últimos livros publicados são: Novas faces da educação superior no Brasil; reforma do estado e mudança na produção, em co-autoria com Valdemar Sguissardi (Bragança Paulista: EDUSF, 1999, $1^{\text {a }}$ edição; e Bragança Paulista e São Paulo: EDUSF e Cortez: 2001, $2^{a}$ edição); Trabalho e formação, em co-autoria com Jorge Luís Cammarano González (São Paulo: Xamã, 2001); e Reformas do estado e da educação no Brasil de FHC (São Paulo: Xamã, 2003). E-mail: joresiju@uol.com.br

\section{Referências bibliográficas}

AGUIAR, Márcia Ângela, SHEIBE, Leda, (1999). Formação de profissionais da educação no Brasil: o curso de pedagogia em questão. Educação e Sociedade, n 68 , número especial sobre formação de profissionais da educação: políticas e tendências, p. 220-238.

BRASIL, Ministério da Educação (1995). Planejamento políticoestratégico 1995/1998. Brasília-DF.

, (1994). Plano decenal de educação para todos. Brasília-DF.

BRESSER PEREIRA, Luiz Carlos, (1996). Crise econômica e reforma do estado no Brasil. Para uma nova interpretação da América Latina. São Paulo: Editora 34. Tradução de Ricardo Ribeiro e Martha Jalkanska.

BRZEZINSKI, Iria, (1999). Embates na definição da política de formação de professores para atuação multidisciplinar nos anos iniciais do ensino fundamental: respeito à cidadania ou disputa pelo poder? Educação e Sociedade, $\mathrm{n}^{\circ} 68$, número 
especial sobre formação de profissionais da educação: políticas e tendências, p. 80-108.

BUENO, Maria Sylvia, (2000). Orientações nacionais para a reforma do ensino médio. Cadernos de Pesquisa, no 109, p. 724, mar.

CARDOSO, Fernando Henrique. Pronunciamento de despedida no Senado Federal, em 14 de dezembro de 1994. Disponível em: <http://legis.senado.gov.br/prodasen>. Acesso em: $21 \mathrm{de}$ outubro de 2003.

CORÁGGIO, José Luís, (1996). Propostas do Banco Mundial para a educação: sentido oculto ou problemas de concepção? In: TOMASI, Lívia et al. (orgs.). O Banco Mundial e as políticas educacionais. São Paulo: Cortez, PUC-SP e Ação Educativa, p. $75-124$.

CUNHA, Maria Isabel da, LÜDKE, Menga, MOREIRA, Flávio Barbosa, (1999). Repercussões de tendências internacionais sobre a formação de nossos professores. Educação e Sociedade, $\mathrm{n}^{\circ} 68$, número especial sobre formação de profissionais da educação: políticas e tendências, p. 278-298.

DAVIES, Nicholas, (2001). O Fundef e as verbas da educação. São Paulo: Xamã.

DUARTE, Newton, (2001). Vigotski e o "aprender a aprender" crítica às apropriações neoliberais e pós-modernas da teoria vigotskiana. Campinas: Autores Associados.

FERRETTI, Celso João, SILVA Jr., João dos Reis, (2000). Educação profissional numa sociedade sem empregos. Cadernos de Pesquisa, no 109 , p. 43-66, mar.

FIORI, José Luís, (1995). Globalização, estados nacionais e políticas públicas. In: FIORI, José Luís. Em busca do dissenso perdido - ensaios críticos sobre a festejada crise do Estado. Rio de Janeiro: Insight Editorial, p. 195-211.

FREITAS, Helena Costa Lopes, (1999). A reforma do ensino superior no campo da formação dos profissionais da educação básica: as políticas educacionais e o movimento dos educadores. Educação e Sociedade, nº 68, número especial sobre formação de profissionais da educação: políticas e tendências, p. 17-44.

GONZÁLEZ, Jorge Luis Cammarano, SILVA Jr., João dos Reis, (2001). Trabalho e formação: uma abordagem ontológica sobre a sociabilidade. São Paulo: Xamã.

KUENZER, Acacia Zeneida, (1999). As políticas de formação: a construção da identidade do professor sobrante. Educação $e$ Sociedade, $\mathrm{n}^{\circ} 68$, número especial sobre formação de profissionais da educação: políticas e tendências, p. 163-183.
LIBÂNEO, José Carlos, PIMENTA, Selma Garrido, (1999). Formação dos profissionais da educação: visão crítica e perspectivas de mudança. Educação e Sociedade, $\mathrm{n}^{\circ}$ 68, número especial sobre formação de profissionais da educação: políticas e tendências, p. 239-277.

LUKÁCS, György, (1983). Per una ontologia dell'essere sociale. Roma: Riuniti.

, (1990). Prolegomini all'ontologia dell' essere sociale. Milão: Guerini e Associati.

MÉZÁROS, István, (2002). Para além do capital; rumo a uma teoria da transição. São Paulo: Boitempo; Campinas: Editora da Unicamp. Tradução de Paulo César Castanheira e Sérgio Lessa.

MOROSINI, Marília (org.), (2001). A educação superior em periódicos nacionais (1968-1995). Brasília: MEC/INEP (Série Estado do Conhecimento).

MOROSINI, Marília, SGUISSARDI, Valdemar (orgs.), (1998). A educação superior em periódicos nacionais. Vitória: Editora da UFES e CNPq.

OLIVEIRA, Francisco, (1992). Color: a falsificação da ira. Rio de Janeiro: Imago.

, (2001). A face do horror. In: SGUISSARDI, Valdemar, SILVA Jr., João dos Reis. As novas faces da educação superior no Brasil: reformas do estado e mudanças na produção. São Paulo: Cortez e EDUSF. Prefácio, p. 7-14.

PALHARINI, Francisco, (1998). Cadernos NUPES: o novo protagonista na formulação teórica da política para o ensino superior. In: MOROSINI, Marília, SGUISSARDI, Valdemar (orgs.). A educação superior em periódicos nacionais. Vitória: Editora da UFES e CNPq, p. 96-112.

POPKEWITZ, Thomas S., (1997). Reforma educacional, uma política sociológica: poder e conhecimento em educação. Porto Alegre: Artes Médicas.

SGUISSARDI, Valdemar (org.), (2000). Educação superior: velhos e novos desafios. São Paulo: Xamã.

SGUISSARDI, Valdemar, SILVA Jr., João dos Reis (orgs.), (2001). Educação superior: análise e perspectivas de pesquisa. São Paulo: Xamã.

SILVA Jr., João dos Reis, (2002c). Breve ensaio sobre o processo civilizatório atual. Revista Avaliação, Campinas, UNICAMP, p. 9-36, set.

, (2002a). Mudanças estruturais no capitalismo mundial e a política educacional do Governo FHC: o caso do ensino 
médio. Educação e Sociedade, Campinas, CEDES, v. 23, no 80 , p. 203-234, out.

, (2002b). A reforma da educação superior dos anos 90: a produção da ciência engajada ao mercado e à produção de um novo pacto social. Sorocaba: Universidade de Sorocaba; São Paulo: PUC/SP (mimeo.).

TORRES, Rosa Maria, (1996). Melhorar a qualidade da educação básica? As estratégias do Banco Mundial. In: TOMASI, Lívia et al. (orgs.). O Banco Mundial e as políticas educacionais. São Paulo: Cortez, PUC-SP e Ação Educativa, 1996, p. 125-194.
, (1998). Tendências da formação docente nos anos 90. In: WARDE, M.J. et al. Novas políticas educacionais: críticas e perspectivas. São Paulo: Entrelinhas, p. 173-192. UNESCO, (1993). Declaração de Nova Delhi. Nova Delhi. , (1990). Declaração mundial sobre educação para todos: satisfação das necessidades básicas de aprendizagem. Jomtien.

Recebido em outubro de 2002

Aprovado em março de 2003 